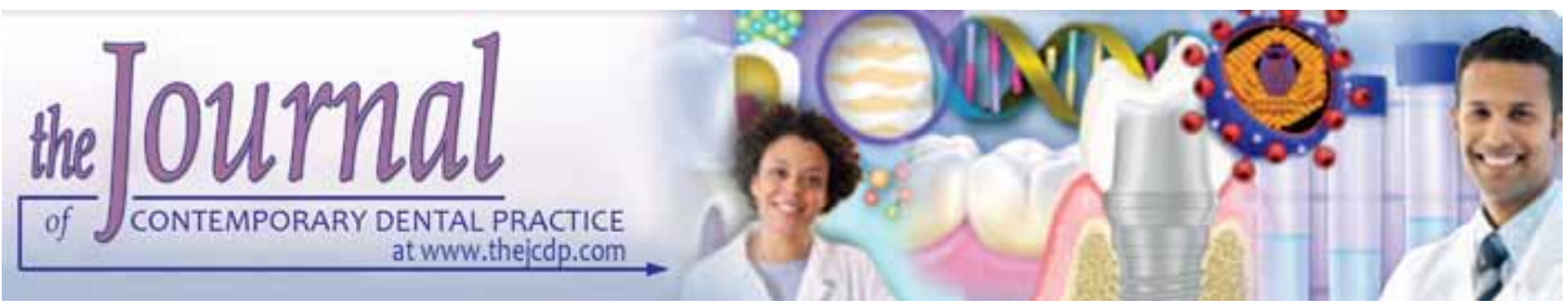

\title{
Is It Possible to induce Artificial Caries-affected Dentin using the Same Protocol to Primary and Permanent Teeth?
}

${ }^{1}$ Tathiane Larissa Lenzi, ${ }^{2}$ Fabio Zovico Maxnuck Soares, ${ }^{3}$ Tamara Kerber Tedesco, ${ }^{4}$ Rachel de Oliveira Rocha

\section{ABSTRACT}

Aim: This in vitro study compared the mineral loss of natural and artificially-created caries-affected dentin in primary and permanent teeth using the same protocol to induce caries lesions.

Materials and methods: Twenty molars presenting natural occlusal dentin caries lesions (10 primary-PriC and 10 permanent-PermC; control group), and 20 sound molars (10 primary PripH and 10 permanent-PermpH; experimental group), were selected. Occlusal cavities were prepared in teeth of the experimental group that were submitted to $\mathrm{pH}$-cycling for 14 days to simulate caries-affected dentin. All specimens were longitudinally sectioned and prepared in order to obtain Knoop microhardness values from 15 to $250 \mu \mathrm{m}$ depth, starting in bottom of center of natural lesions or cavities. The microhardness $(\mathrm{KHN})$ data were submitted to three-way repeated measures analysis of variance (ANOVA) and Tukey's tests $(\alpha=0.05)$.

Results: Considering all depths, there was no statistically significant differences $(p>0.05)$ between the mineral loss of the control (PriC $=30.9 \pm 6.4$ and PermC $=40.8 \pm 8.6$ ) and experimental $(\mathrm{PripH}=27.3 \pm 11.1$ and $\mathrm{PermpH}=35.5 \pm 14.0)$ groups, neither between primary and permanent teeth.

Conclusion: The mineral loss of the artificially-created cariesaffected dentin is similar to that from naturally developed dentin caries lesions.

${ }^{1}$ Department of Stomatology, Federal University of Santa Maria, Rua Floriano Peixoto, RS, Brazil

${ }^{2}$ Department of Restorative Dentistry, Federal University of Santa Maria, Rua Floriano Peixoto, RS, Brazil

${ }^{3,4}$ Department of Stomatology, University of Santa Maria, Rua Floriano Peixoto, RS, Brazil

Corresponding Author: Rachel de Oliveira Rocha, Associate Professor, Department of Stomatology, Federal University of Santa Maria, Rua Floriano Peixoto, 1184-Santa Maria RS-97015-372, Brazil, Phone: +55 55 32209272, e-mail: rachelrocha@smail.ufsm.br
Clinical significance: The $\mathrm{pH}$-cycling model may be a suitable method to simulate caries-affected dentin in both permanent and primary teeth.

Keywords: Dental caries, Deciduous dentition, Dentin, Hardness, Laboratory research, Permanent, Tooth.

How to cite this article: Lenzi TL, Soares FZM, Tedesco TK, de Oliveira Rocha R. Is ItPossible to induceArtificial Caries-affected Dentin using the Same Protocol to Primary and Permanent Teeth? J Contemp Dent Pract 2015;16(8):638-642.

Source of support: Nil

Conflict of interest: None

\section{INTRODUCTION}

The actual concepts of minimal intervention (MI) dentistry are characterized by a better understanding of the caries process and ultraconservative approaches for treating cavitated dentin lesions. ${ }^{1}$ In clinical situation, the bonding surface that is most frequently encountered after caries excavation consists of caries-affected dentin (CAD), which has prompted the investigation of restorative materials' performance on this substrate.

Contemporary studies have evaluated not only the bond strength of different adhesive materials to CAD, but also the resin-dentin bonds stability on this substrate and different caries excavation techniques. ${ }^{2-8}$ Nevertheless, the large variability in activity status, shape, size, depth of natural CAD as well as structural differences within different carious zones create technical difficulties in obtaining this substrate in a standardized way for testing materials and new techniques. ${ }^{2,9}$ This is especially critical for primary teeth, due to their reduced thickness of enamel and dentin, that often leads to pulp chamber involvement. Furthermore, several structural characteri stics of natural carious dentin can be related to controversial results regarding the adhesion to $\mathrm{CAD}$. Some investigations 
have showed lower bond strength values to CAD as compared to sound dentin, while others showed higher bond strength to CAD or similar values between substrates. ${ }^{10-14}$

In an attempt to overcome difficulties when using natural caries-affected dentin, artificial methods have been proposed to create in vitro caries-like lesions. ${ }^{4,15-18}$ The $\mathrm{pH}$-cycling dynamic model has been widely employed for the development of enamel lesions, the reason for which it was proposed, and nowadays, to simulate artificial caries dentin. ${ }^{15,19,20}$

Marquezan et al verified that $\mathrm{pH}$-cycling promotes a caries-affected dentin layer with superficial demineralization, with similar hardness values as naturally CAD in primary teeth. ${ }^{15}$ It has been evidenced that primary and permanent dentin present chemical and microstructural differences. ${ }^{21}$ In view that the concentration of calcium and phosphate in the peritubular and intertubular dentin of permanent teeth is higher as compared to primary ones, studies are necessary to evaluate if the same caries induction protocol can be applied on both substrates. ${ }^{21}$

Since microhardness test has been used to indirectly evaluate mineral content of dental substrates, the aim of this in vitro study was to compare the mineral loss of natural and artificially-created CAD in primary and permanent teeth using the same protocol to induce caries lesions, by hardness evaluation. ${ }^{2,22}$

\section{MATERIALS AND METHODS}

\section{Selection and Teeth Preparation}

This research protocol received approval from the research ethics committee. Twenty carious and 20 sound human teeth, half of them primary (Pri) molars and the other half permanent (Perm) molars, were selected from a tooth bulk. Teeth were disinfected with $0.5 \%$ chloramine and stored in distilled water at $4^{\circ} \mathrm{C}$ until use.

Primary and permanent molars presenting caries lesions on the occlusal surface with $2 \pm 0.5 \mathrm{~mm}$ depth from amelodentinal junction measured with a periodontal probe, after longitudinal cut, were included in this study and considered as naturally caries-affected dentin group (control group: C group).

Teeth from $C$ groups were longitudinally sectioned in the center of the lesion with a water-cooled low-speed diamond saw (Extec 12205, Extec Co, Enfield, USA), mounted in a cutting machine (Labcut 1010, Extec Co, Enfield, USA), and then immediately prepared for the hardness evaluation.

Sound primary and permanent molars that comprised the experimental groups (pH groups) were submitted to a pH-cycling model to simulate artificial caries-affected dentin. Occlusal cavities $(2 \times 4 \times 2 \mathrm{~mm})$ were prepared using a diamond bur (2094 KG Sorensen, São Paulo, Brazil) with a high-speed handpiece with water spray. Teeth had their cervical portions sealed with quicksetting epoxy resin (Araldite Hobby, Ciba Especialidades Químicas Ltd., São Paulo, SP, Brazil), and rendered waterproof with two layers of acid-resistant nail polish (Colorama Maybelline Ltd., São Paulo, SP, Brazil), with the exception of inner part of the cavities.

Specimens were then individually immersed in $10 \mathrm{ml}$ of demineralizing solution $\left(2.2 \mathrm{mM} \mathrm{CaCl}_{2}, 2.2\right.$ $\mathrm{mM} \mathrm{NaH} \mathrm{PO}_{4}, 50 \mathrm{mM}$ acetic acid; adjusted $\mathrm{pH}$ of 4.8) for 8 hours and in the same volume of remineralizing solution $\left(1.5 \mathrm{mM} \mathrm{CaCl}_{2}, 0.9 \mathrm{mM} \mathrm{NaH}_{2} \mathrm{PO}_{4}, 0.15 \mathrm{mM} \mathrm{KCl}\right.$; adjusted $\mathrm{pH}$ of 7.0 ) for 16 hours. ${ }^{15}$ After immersions, the teeth were rinsed with deionized water. This procedure was carried out for 14 days at room temperature without agitation. At the end of $\mathrm{pH}$-cycling period, teeth were longitudinally sectioned in the center of the cavities in the same way as for teeth of $C$ groups.

\section{Hardness Evaluation}

Two halves of each teeth were embedded in epoxy resin (Buehler Ltd., Lake Bluff, IL, USA), so that the area to be analyzed remained exposed. Polishing was performed using a polishing cloth (Ecomet 4 , Buehler, Lake Bluff, IL, USA) with 320, 480, 600, 1200, 2500 and 4000-grit silicon carbide abrasive papers, and final polishing was made with diamond paste of $1 \mu \mathrm{m}$ and $0.25 \mu \mathrm{m}$ (Buehler Ltd., Lake Bluff, IL, USA). After the last stage of polishing, the specimens were ultrasonically cleaned to remove eventual residues.

Fifteen indentations were made in the center of the caries lesions (C groups) or cavities (pH groups) and $100 \mu \mathrm{m}$ on each side, at depths of 15, 40, 100, 150 and $250 \mu \mathrm{m}$ using a Knoop indenter, with a static load of $25 \mathrm{gm}$ for 30 seconds coupled with HMV II microhardness tester (HMV II, Shimadzu, Kyoto, Japan).

\section{STATISTICAL ANALYSIS}

The experimental unit in this study was the tooth. Thus, microhardness values means for all experimental groups was expressed as the average of the 10 teeth used per group. Additionally, from each specimen, at each depth from the pulp floor, the average was obtained considering the three measurements (center and $100 \mu \mathrm{m}$ on each side).

The normal distribution of the data was confirmed using Kolmogorov-Smirnov test. Microhardness data were subjected to three-way repeated measures analysis of variance (ANOVA), using a factorial design with group (natural CAD vs artificial CAD-pH-cycling), indentation depth and tooth type (primary and permanent teeth) as 
variables. The clustered variable was the indentation depth. Tukey's HSD multiple comparisons statistical test at a 0.05 significance level was used. Statistical analysis was performed with GMC software, version 7.7.

\section{RESULTS}

Graph 1 summarizes the microhardness (KHN) values as function of depth for all experimental groups.

The results of the microhardness testing did not show statistically significant differences $(p>0.05)$ in mineral loss between natural and artificially-created CAD. The same way, the mineral loss was similar ( $p>0.05)$ between primary and permanent teeth in all depths.

\section{DISCUSSION}

The irregular characteristics of natural caries dentin associated to difficulty in obtaining this substrate in a standardized way for in vitro investigations has instigated the development of different models to induce caries-like lesions.

Considering the influence of chemical differences between primary and permanent dentin in development pattern of artificial caries lesions, this is a pioneering investigation that assessed if same protocol using $\mathrm{pH}-$ cycling model could be applied to both substrates.

In our study, the mineral loss was similar between primary and permanent teeth, irrespective of the indentation depth. Despite of the discrepancies in mineral content, this result validates the use of the same protocol ( $\mathrm{pH}$-cycling for 14 days, using a demineralizing solution with adjusted $\mathrm{pH}$ of 4.8 ) to artificially induce CAD in both substrates.

The mean microhardness values were similar between natural and artificial caries-affected dentin groups. However, the standard deviations were greater in $\mathrm{C}$ groups, especially in primary teeth (Graph 1). These findings reflect the variability of the naturally developed dentin caries lesions which occur over long periods of time, in contrast to the artificially-created CAD, where the lesion was created in a short period of time under controlled conditions. These findings corroborate a previous study that compared the mineral content of natural and artificially-created caries-affected permanent dentin, by an another $\mathrm{pH}$-cycling model, at different depth levels until $150 \mu \mathrm{m} .{ }^{17}$ Recently, Joves et al also demonstrated that natural and artificial caries-affected dentin tissues of permanent teeth were superficially comparable in intertubular nanohardness. ${ }^{23}$

Among the chemical and microbiological methods of dentin caries induction, the $\mathrm{pH}$-cycling model has been considered the most appropriate design to simulate

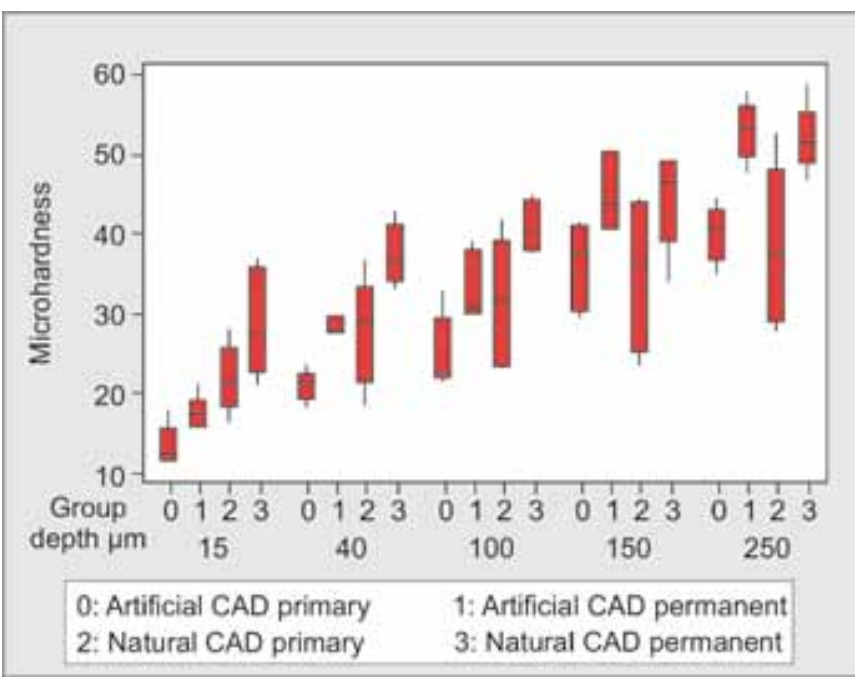

Graph 1: Mineral loss as function of depth for all experimental groups $(p>0.05)$

the carious process, since it promotes alternate periods of demineralizing and remineralizing; although the real duration these periods in the oral environment is unknown. ${ }^{24,25}$ According to a previous study, microbiological method is more aggressive than $\mathrm{pH}$-cycling in primary teeth, especially until $100 \mu \mathrm{m}$ depth. ${ }^{15}$ Additionally, this method seems more indicated to simulate an infected layer of dentin caries lesion, not caries-affected dentin, which is considered the appropriate substrate to perform bonding approaches in clinical situations.

In turn, the lowest hardness values obtained for artificially-induced CAD were also similar to that reported by Fusayama and Terashima for transparent dentin, which exists beneath carious lesions. ${ }^{26,27}$ It is important to highlight that despite the absence of statistically significant difference among the depths evaluated, at $250 \mu \mathrm{m}$ depth the values were near to sound dentin hardness. Based on that, this method of caries induction seems to promote a slightly superficial demineralization. Marquezan et al also demonstrated that $\mathrm{pH}$-cycling method provided similar hardness values in comparison to naturally caries-affected dentin of primary teeth until the depth $40 \mu \mathrm{m}$, and lower values than sound dentin until depth of $200 \mu \mathrm{m} .{ }^{15}$

Despite similarity in mineral loss between types of caries-affected dentin, the formation mechanisms are different. Natural caries lesions show two layers of the carious dentin: a portion of soft and moist dentin highly infected for bacteria, and a layer of affected dentin. ${ }^{28}$ The caries-affected dentin layer, although is demineralized and contains dentinal tubules occluded by acid-resistant mineral crystals, shows viable odontoblastic processes and normal collagen, suitable of remineralization. ${ }^{26}$

One limitation of the simulation of artificial CAD in extracted or exfoliated teeth is that the reaction of the dentin pulp complex to the demineralization process, represented by tubular occlusion with acid-resistant 
whitlockite minerals, is not present, differing somewhat with the clinical situation. Thus, we speculate that the artificial caries-affected dentin presents such aspects to an acute natural caries lesion.

Besides substrate demineralization, in vivo lesion formation in dentin involves the degradation of the exposed organic matrix by metaloproteinases (MMPs) activated by acidic conditions and proteinases from microorganisms of the carious process. ${ }^{29,30}$ It must be emphasized that in vitro caries-like lesions cannot accomplish all factors involved in the carious process. When $\mathrm{pH}$-cycling method is considered, the demineralization of the substrate is characterized by the absence of bacteria. Nevertheless, the greatest advantage of this method is the possibility of the fast and reliable formation of the carious lesions, providing more homogenous dentin surfaces. ${ }^{24,25}$ Therefore, the $\mathrm{pH}$-cycling method seems be a suitable method to simulate CAD for several purposes, mainly for bond strength analysis, irrespective of tooth type (primary or permanent).

\section{CONCLUSION}

The mineral loss of the artificially-created caries-affected dentin is similar to that from the naturally developed dentin caries lesions for both primary and permanent teeth.

\section{CLINICAL SIGNIFICANCE}

The pH-cycling model may be a suitable method to simulate caries-affected dentin in both permanent and primary teeth.

\section{REFERENCES}

1. Murdoch-Kinch CA, McLean ME. Minimally invasive dentistry. J Am Dent Assoc 2003;134(1):87-95.

2. Erhardt MC, Rodrigues JA, Valentino TA, Ritter AV, Pimenta LA. In vitro microTBS of one-bottle adhesive systems: sound versus artificially-created caries-affected dentin. J Biomed Mater Res B Appl Biomater 2008;86(1):181-187.

3. Alves FB, Lenzi TL, Reis A, Loguercio AD, Carvalho TS, Raggio DP. Bonding of Simplified Adhesive Systems to Caries-affected Dentin of Primary Teeth. J Adhes Dent 2013; 15(5):439-445.

4. Zanchi CH, Lund RG, Perrone LR, Ribeiro GA, del Pino FA, Pinto MB, Demarco FF. Microtensile bond strength of twostep etch-and-rinse adhesive systems on sound and artificial caries-affected dentin. Am J Dent 2010;23(3):152-156.

5. Ricci HA, Sanabe ME, de Souza Costa CA, Pashley DH, Hebling J. Chlorhexidine increases the longevity of in vivo resin-dentin bonds. Eur J Oral Sci 2010;118(4):411-416.

6. Marquezan M, Osorio R, Ciamponi AL, Toledano M. Resistance to degradation of bonded restorations to simulated caries-affected primary dentin. Am J Dent 2010;23(1):47-52.

7. Neves Ade A, Coutinho E, Cardoso MV, de Munck J, Van Meerbeek B. Micro-tensile bond strength and interfacial characterization of an adhesive bonded to dentin prepared by contemporary caries-excavation techniques. Dent Mater 2011;27(6):552-562.

8. Yildiz E, Sirinkaraarslan E, Yegin Z, Cebe MA, Tosun G. Effect of caries removal techniques on the bond strength of adhesives to caries-affected primary dentin in vitro. Eur J Paediatr Dent 2013;14(3):209-214.

9. Zavgorodniy AV, Rohanizadeh R, Swain MV. Ultrastructure of dentine carious lesions. Arch Oral Biol 2008;53(2):124-132.

10. Scholtanus JD, Purwanta K, Dogan N, Kleverlaan CJ, Feilzer AJ. Microtensile bond strength of three simplified adhesive systems to caries-affected dentin. J Adhes Dent 2010;12(4):273-278.

11. Mobarak EH, El-Badrawy WH. Microshear bond strength of self-etching adhesives to caries-affected dentin identified using the dye permeability test. J Adhes Dent 2012;14(3):245-250.

12. Nakornchai $S$, Harnirattisai $C$, Surarit R, Thiradilok S. Microtensile bond strength of a total-etching versus selfetching adhesive to caries-affected and intact dentin in primary teeth. J Am Dent Assoc 2005;136(4):477-483.

13. Hosoya Y, Kawada E, Ushigome T, Oda Y, Garcia-Godoy F. Micro-tensile bond strength of sound and caries-affected primary tooth dentin measured with original designed jig. J Biomed Mater Res B Appl Biomater 2006;77(2):241-248.

14. Tosun G, Koyuturk AE, Sener Y, Sengun A. Bond strength of two total-etching bonding systems on caries-affected and sound primary teeth dentin. Int J Paediatr Dent 2008;18(1): 62-69.

15. Marquezan M, Correa FN, Sanabe ME, Rodrigues Filho LE, Hebling J, Guedes-Pinto AC, Mendes FM. Artificial methods of dentine caries induction: A hardness and morphological comparative study. Arch Oral Biol 2009;54(12):1111-1117.

16. Sanabe ME, Costa CA, Hebling J. Exposed collagen in aged resin-dentin bonds produced on sound and caries-affected dentin in the presence of chlorhexidine. J Adhes Dent 2011; 13(2):117-124.

17. Joves GJ, Inoue G, Nakashima S, Sadr A, Nikaido T, Tagami J. Mineral density, morphology and bond strength of natural versus artificial caries-affected dentin. Dent Mater J 2013;32(1): 138-143.

18. Lenzi TL, Tedesco TK, Soares FZ, Loguercio AD, Rocha Rde O. Chlorhexidine does not increase immediate bond strength of etch-and-rinse adhesive to caries-affected dentin of primary and permanent teeth. Braz Dent J 2012;23(4):438-442.

19. ten Cate JM, Duijsters PP. Alternating demineralization and remineralization of artificial enamel lesions. Caries Res 1982;16(3):201-210.

20. Lenzi TL, Mendes FM, de Oliveira Rocha R, Raggio DP. Effect of Shortening the Etching Time on Bonding to Sound and Caries-affected Dentin of Primary Teeth. Pediatr Dent 2013;35(5):129-133.

21. Angker L, Nockolds C, Swain MV, Kilpatrick N. Quantitative analysis of the mineral content of sound and carious primary dentine using BSE imaging. Arch Oral Biol 2004;49(2):99-107.

22. Craig RG, Gehring PE, Peyton FA. Relation of structure to the microhardness of human dentin. J Dent Res 1959;38(3): 624-630.

23. Joves GJ, Inoue G, Sadr A, Nikaido T, Tagami J. Nanoindentation hardness of intertubular dentin in sound, demineralized and natural caries-affected dentin. J Mech Behav Biomed Mater 2013;32:39-45.

24. Hara AT, Queiroz CS, Giannini M, Cury JA, Serra MC. Influence of the mineral content and morphological pattern of 
artificial root caries lesion on composite resin bond strength. Eur J Oral Sci 2004;112(1):67-72.

25. Featherstone JD. Modeling the caries-inhibitory effects of dental materials. Dent Mater 1996;12(3):194-197.

26. Fusayama T, Terashima S. Differentiation of two layers of carious dentin by staining. Bull Tokyo Med Dent Univ 1972; 19(1):83-92.

27. Ogawa K, Yamashita Y, Ichijo T, Fusayama T. The ultrastructure and hardness of the transparent layer of human carious dentin. J Dent Res 1983;62(1):7-10.
28. Fusayama T, Okuse K, Hosoda H. Relationship between hardness, discoloration, and microbial invasion in carious dentin. J Dent Res 1966;45(4):1033-1046.

29. Pashley DH, Tay FR, Yiu C, Hashimoto M, Breschi L, Carvalho RM, Ito S. Collagen degradation by host-derived enzymes during aging. J Dent Res 2004;83(3):216-221.

30. Tjaderhane L, Larjava H, Sorsa T, Uitto VJ, Larmas M, Salo T. The activation and function of host matrix metalloproteinases in dentin matrix breakdown in caries lesions. J Dent Res 1998; 77(8):1622-1629. 